\title{
Role of Light and Malate in the Decreased Sensitivity of cms-T Cytoplasm Maize Leaves to Bipolaris maydis Race T Toxin
}

\author{
M. O. Garraway, D.-S. Park, and J. D. Beltran
}

Department of Plant Pathology, Ohio Agricultural Research and Development Center, The Ohio State University, Columbus 43210. Accepted for publication 9 March 1998.

\begin{abstract}
Garraway, M. O., Park, D.-S., and Beltran, J. D. 1998. Role of light and malate in the decreased sensitivity of cms-T cytoplasm maize leaves to Bipolaris maydis race T toxin. Phytopathology 88:556-562.

Leaf segments from Texas male sterile (cms-T) cytoplasm maize isolines exposed to light $\left(50 \mu \mathrm{M} \mathrm{s}^{-1} \mathrm{~m}^{-2}\right)$ for $8 \mathrm{~h}$ or more before or after being infiltrated with the Bipolaris maydis race $\mathrm{T}$ toxin (T-toxin) leaked significantly less electrolytes when immersed in distilled water (DW) for 24 to $48 \mathrm{~h}$ than did dark-treated leaf segments. No comparable effect of light on toxin-induced electrolyte leakage was observed with normal $(\mathrm{N})$ cytoplasm isolines. Toxintreated cms-T leaf segments incubated in DW for three consecutive 12-h periods of alternating light and dark showed significantly greater electrolyte leakage than leaf segments incubated in continuous light for $36 \mathrm{~h}$ and sig-
\end{abstract}

ABSTRACT nificantly less leakage than segments incubated in continuous dark for $36 \mathrm{~h}$. Exposure of cms-T, but not N, cytoplasm leaves to 25 or $50 \mu \mathrm{M}$ malic acid decreased their sensitivity to T-toxin in the dark to a level similar to that observed when leaves were incubated in the light without malic acid. The potency of T-toxin appeared to be unaffected by its exposure to light. The loss of electrolytes from T-toxin-treated cms-T cytoplasm leaf segments was at approximately the level seen with light or malate when $25 \mu \mathrm{M} \mathrm{H}_{2} \mathrm{O}_{2}$ was added to the DW bathing solution. Evaluation of the data points to the possibility that $\mathrm{H}_{2} \mathrm{O}_{2}$ might be involved with the altered sensitivity of cms-T cytoplasm leaves to T-toxin caused by either light or malate.

Additional keywords: Cochliobolus heterostrophus, disease resistance, hydrogen peroxide, $\mathrm{N}$ cytoplasm maize.
The effects of light on the responses of normal $(\mathrm{N})$ and Texas male sterile (cms-T) cytoplasm maize (Zea mays L.) leaves to the host-selective toxin from Bipolaris maydis race $\mathrm{T}$ (T-toxin) were first noted by Bhullar et al. (6). Light caused enhanced bleaching of toxin-treated cms-T cytoplasm maize leaves. Also, Daly and Barna (9) noted that the potency of toxin, as measured by $\mathrm{CO}_{2}$ fixation by cms-T leaves, was increased by light. The significance of these observations is somewhat obscured by the various effects of light on the sensitivity of cms-T maize to T-toxin noted by others. For example, MacRae and Yoder (35) observed that protoplasts from etiolated leaves were insensitive to T-toxin when left in the dark, but became sensitive if the etiolated leaves were exposed to light prior to the assay of the protoplasts. On the other hand, protoplasts from green leaves that were preincubated in the dark were sensitive to T-toxin, but became insensitive when the leaves were exposed to light before the protoplasts were used in the toxin assay.

Differing explanations have been given for the stimulatory $(6,9)$ and inhibitory $(35,50)$ effects of light on the sensitivity of cms-T leaves to T-toxin. Because we have observed that light decreases the sensitivity of cms-T leaves to T-toxin (4), the studies of Walton et al. (50) are of interest. They showed that the level of ATP in toxin-treated mesophyll protoplasts declined less rapidly in the light than in the dark, and they suggested that light could decrease the sensitivity of cms-T maize leaves to toxin by light-driven phosphorylation. However, the contrasting observations of the effects of light $(6,9,35)$ indicate that the mechanisms by which it affects the sensitivity of cms-T maize to T-toxin have been neither completely understood nor fully explained.

Molecular geneticists and biologists have shown that cms-Tinduced male sterility associated with maternal inheritance of sensitivity to T-toxin is due to the presence of a mitochondrial gene designated T-urf $13(33,47)$. A $13-\mathrm{kDa}$ polypeptide is the product of the

Corresponding author: M. O. Garraway; E-mail address: garraway.1@osu.edu

Publication no. P-1998-0414-01R

(C) 1998 The American Phytopathological Society gene, and it is a component of the inner mitochondrial membrane $(11,52)$. Reports that the T-urf 13 gene confers sensitivity to the toxin when it is expressed in Escherichia coli (12) or in Saccharomyces cerevisiae (20), together with tissue culture studies involving cms-T revertants $(49,53)$, provide the molecular basis for the link of cms-T-induced male sterility and cms-T-induced sensitivity to toxin (33). Since the 13-kDa protein of the mitochondrion of cms-T maize is the site of action of T-toxin, light suppression would be assumed to be due to chloroplast compensation for defective mitochondria in supplying ATP and reducing potential to the cell (50). However, this interpretation does not explain the stimulatory effect of light on toxin action reported by Bhullar et al. (6) and Daly and Barna (9) or by MacRae and Yoder (35) with etiolated protoplasts.

The T-toxin causes multiple biochemical effects in susceptible cms-T cytoplasm maize tissues that are associated with its mitochondrial site of action. In the presence of T-toxin, mitochondria isolated from cms-T cytoplasm maize display increased leakage of $\mathrm{NAD}^{+}$and coenzyme A $(5,37)$, altered permeability to anions and cations $(24,30,38)$, reversible swelling $(19,31)$, depolarization of the membrane $(5,39)$, changes in the rate of substrate oxidation $(3,40$, $45)$, and uncoupling of $\mathrm{NADH}+\mathrm{H}^{+}$from ATP synthesis $(3,5,20)$.

Since the organelle primarily affected by the action of light in green leaves is the chloroplast $(15,23,28)$, it is possible that the influence of light on the sensitivity of maize leaves to T-toxin involves, in addition to ATP and NADPH $+\mathrm{H}^{+}$, metabolites derived directly or indirectly from light-activated processes in the chloroplast. In plants such as maize, $\mathrm{CO}_{2}$ is transferred via the $\mathrm{C}-4$ carboxyl of $\mathrm{C}_{4}$ acids to the reactions of the photosynthetic carbon reduction (PCR) cycle and is there reduced to the level of carbohydrate $(23,29)$. The distinctive biochemical features of this process, known as $\mathrm{C}_{4}$ photosynthesis, are the carboxylation and associated reactions leading to the synthesis of $\mathrm{C}_{4}$ acids and those concerned with subsequent decarboxylation of $\mathrm{C}_{4}$ acids to supply $\mathrm{CO}_{2}$ for the PCR cycle (23). Another distinctive feature of the $\mathrm{C}_{4}$ pathway of photosynthesis is that it involves the transport of intermediates between intracellular compartments such as chloroplasts and mitochondria, as well as between cells (23). 
The studies of Gengenbach et al. (19) support the idea that malate and related metabolites could play a mediating role in the lightmodulated response of cms-T maize to T-toxin. They measured the effect of T-toxin on state 4 oxygen uptake by mitochondria from cms-T and $\mathrm{N}$ cytoplasm maize. With NADH as the substrate, $\mathrm{O}_{2}$ uptake by mitochondria from cms-T maize was enhanced in the presence of T-toxin, presumably by promoting uncoupling. On the other hand, with malate as a substrate, $\mathrm{O}_{2}$ uptake by isolated mitochondria was inhibited in the presence of toxin, presumably by preventing uncoupling. No such effects of these substrates on $\mathrm{O}_{2}$ uptake in response to toxin were seen with mitochondria from $\mathrm{N}$ cytoplasm maize. These effects of malate on state 4 oxygen uptake have been observed by others (43). Thus, $\mathrm{C}_{4}$ metabolites may mediate the effect of light on the sensitivity of cms-T maize to Ttoxin through an effect on mitochondrial metabolism.

The production and accumulation of active oxygen species (AOS) has been shown to occur in a variety of plant-pathogen systems. Also, AOS may accumulate under stress associated with toxic metabolites produced by infectious pathogens $(1,32)$ or by environmental stresses such as high light $(7,41)$ and extremes of temperature $(14,22,27)$. Therefore, the possibility that AOS might be involved with the effect of light on the response of cms-T maize leaves to toxin is of interest.

Based on the above considerations and on our previous observations (4), the objectives of this study were to determine the effect of light on the sensitivity of $\mathrm{N}$ and cms- $\mathrm{T}$ cytoplasm maize leaves to T-toxin as measured by electrolyte leakage; evaluate the effect of the $\mathrm{C}_{4}$ metabolites, malic and aspartic acids, on this sensitivity; and propose an explanation for the action of either light or malate on the decreased sensitivity of cms-T maize to T-toxin.

\section{MATERIALS AND METHODS}

Host. Maize inbreds B37, OH43, and W64A with N or cms-T cytoplasms were grown in 24-cm-diameter pots, three plants per pot, in a steam-sterilized mixture of perlite/peat moss/loam (1:1:1). The plants were maintained in the greenhouse at a temperature of $28^{\circ} \mathrm{C}$ during the day and $24^{\circ} \mathrm{C}$ at night. Plants were watered and fertilized alternately with a soluble $20-20-20$ fertilizer at the rate of $200 \mathrm{ppm}$. Plants used for the experiments were 4 to 5 weeks old. Leaves of similar age were detached from each isoline, washed with distilled water (DW), and then cut into strips 16 by $1.5 \mathrm{~cm}$ and used in the experiments described below.

Toxin preparation. A single-spore isolate of Cochliobolus heterostrophus (Drechs.) Drechs. (Bipolaris maydis (Nisikado \& Miyake) Shoemaker) race $\mathrm{T}$ recovered from an ear of maize from a field in Franklin County, OH, in 1970 (ATCC 36180) was grown for 7 days on a xylose-glucose-L-asparagine-mineral salts agar medium as previously described $(16,17)$. The toxin solution was prepared by the procedure of Bednarski et al. (3) with the following modifications. Agar cultures were homogenized in two volumes of methanol. The homogenate was filtered, with $\mathrm{pH}$ of the filtrate adjusted to 4.5 , and then concentrated in a rotary evaporator at reduced pressure to $10 \%$ of the original volume. Two volumes of methanol was then added, and the preparation was held overnight at $4{ }^{\circ} \mathrm{C}$. A precipitate was removed followed by the removal of methanol at reduced pressure to $20 \%$ of the original volume. The resulting aqueous solution was partitioned three times with equal volumes of chloroform. Chloroform extracts were pooled, concentrated in vacuo, and then dissolved in $50 \%$ ethanol. This partially purified soluble toxin preparation was stable in storage $\left(-15^{\circ} \mathrm{C}\right)$. The toxin was purified further by applying $2.0-\mathrm{ml}$ aliquots to a Sephadex LH-20 column (particle size 25 to $100 \mu \mathrm{m}$, column dimensions $1.5 \times 30 \mathrm{~cm}$; Amersham Pharmacia Biotech, Piscataway, NJ) and eluting with $80 \%$ ethanol at a flow rate of 2.0 $\mathrm{ml} / \mathrm{min}$. The toxin-containing aliquots prepared in this way were stored in $80 \%$ ethanol and referred to as T-toxin. They were several times more potent than the partially purified toxin preparation, as measured by electrolyte leakage from toxin-treated $\mathrm{cms}-\mathrm{T}$ maize leaves. Also, by measuring differences in electrolyte leakage from toxin-treated leaves, it was possible to distinguish $\mathrm{N}$ from $\mathrm{cms}-\mathrm{T}$ maize with similar results to those of others $(43,44)$.

Toxin assay. Leaf strips were placed cut-end down into vials containing T-toxin in $2 \%$ aqueous ethanol. Infiltration of leaf strips was carried out by allowing them to take up the toxin solutions in the transpiration stream in the dark at $28^{\circ} \mathrm{C}$ for $24 \mathrm{~h}$, except for those treatments to be described later in which the effect of the light regime during infiltration was evaluated. The concentrations of T-toxin used in the study were estimates and were designated as $0.04,0.1$, or $0.2 \mu \mathrm{g} / \mathrm{ml}$. These estimates were based on the increments of electrolyte loss from cms-T maize leaves treated with a series of T-toxin dilutions in $2 \%$ aqueous ethanol. The quantitative results were calibrated against the published findings of Payne and Yoder (45), who worked with highly purified preparations of Ttoxin. Following infiltration, the leaves were rinsed in DW and the immersed ends cut off. The trimmed leaves were then cut into five $3 \times 1.5-\mathrm{cm}$ segments, and each was immersed in a bathing solution of $25 \mathrm{ml}$ of DW as previously described $(17,18)$. In two of the experiments reported below on the effects of light, malic acid, and $\mathrm{H}_{2} \mathrm{O}_{2}$, leaf segments, instead of being infiltrated with $0.2 \mu \mathrm{g}$ of Ttoxin per $\mathrm{ml}$ of $2 \%$ ethanol solution, were immersed directly into a DW bathing solution of $0.04 \mu \mathrm{g}$ of T-toxin per $\mathrm{ml}$ of $0.5 \%$ ethanol solution. This altered protocol was adopted because cms-T tissues were more sensitive to T-toxin when assayed with this method. Also, although the results were more variable, this approach involved fewer manipulations and facilitated the more efficient acquisition of data from the very large number of treatments involved in the study.

The initial conductivity of the bathing solution was measured with a conductivity cell (model 4973) attached to a conductivity bridge (model 4959; Leeds and Northrup Co., Philadelphia). The immersed segments were incubated either in the dark or the light or in alternating light and dark for up to $36 \mathrm{~h}$. The conductivity of the bathing solution was measured at 6-, 12-, and 24-h intervals. The change in conductivity was computed, and the values were used as an indication of electrolyte leakage from leaves. At the end of each experiment, the leaf segments were dried at $80^{\circ} \mathrm{C}$ and the dry weights determined.

The protocols described above were used in a series of experiments designed to test the potency and selectivity of the toxin preparations and the effects of light, malate, aspartate, and $\mathrm{H}_{2} \mathrm{O}_{2}$ on the sensitivity of cms-T cytoplasm maize to T-toxin as measured by electrolyte leakage. All experiments were performed at least three times, with five replicates in each. Data were calculated as the means \pm the standard deviations of five replicates and were obtained from three separate experiments. Differences between treatments were considered significant when the standard deviation values did not overlap. Also, treatment comparisons were significant at the $99 \%$ confidence level based on Student's $t$ test.

\section{RESULTS}

Effect of T-toxin on leakage from $\mathrm{N}$ and cms-T cytoplasm maize. This study was undertaken to insure that the toxin preparations used had similar selectivity to that prepared by the method of Bednarski et al. (3) or Payne and Yoder (45). The T-toxin caused a significant increase in electrolyte leakage from cms- $\mathrm{T}$, but not $\mathrm{N}$, cytoplasm leaf segments. Moreover, an increase in the toxin concentration in the infiltration solution from 0.1 to $0.2 \mu \mathrm{g} / \mathrm{ml}$ caused an increase in the electrolyte leakage from cms- $T$ leaves. Moreover, the amount of electrolytes lost increased in magnitude with increasing concentrations of T-toxin in the $2 \%$ ethanol solution used to infiltrate the cms-T maize leaves (Fig. 1). These observations are consistent with other studies involving the use of purified or partially purified preparations of T-toxin $(44,45,51)$.

Effect of preincubation of cms-T cytoplasm leaves in light on T-toxin-induced electrolyte leakage. For this study, cms-T cytoplasm leaves from cultivar W64A were detached from 4-weekold maize plants, kept overnight in the dark, cut into $16 \times 1.5-\mathrm{cm}$ 
strips, and then the ends were immersed in vials with $5 \mathrm{ml}$ of DW. The leaf strips were exposed to either 0,2 , or $8 \mathrm{~h}$ of light $\left(50 \mu \mathrm{M} \mathrm{s}^{-1} \mathrm{~m}^{-2}\right)$ during $8 \mathrm{~h}$ of preincubation at $28^{\circ} \mathrm{C}$. The preincubated strips were then infiltrated in the dark for $24 \mathrm{~h}$ with solutions of $2 \%$ ethanol or $2 \%$ ethanol containing approximately 0.1 or $0.2 \mu \mathrm{g}$ of T-toxin per $\mathrm{ml}$. Three-centimeter segments from these leaf strips were immersed in $25 \mathrm{ml}$ of DW and then incubated for up to $48 \mathrm{~h}$ in the dark at $28^{\circ} \mathrm{C}$. T-toxin caused a significant increase in electrolyte leakage from cms-T leaves whether or not they were exposed to light prior to infiltration (Fig. 2). However, leaf segments that were exposed to light lost less electrolytes than those that were

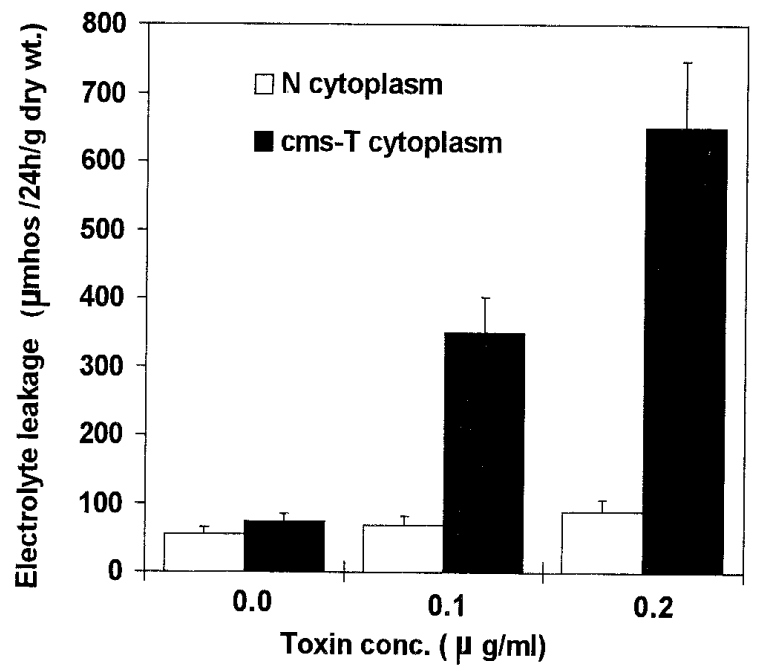

Fig. 1. Effect of Bipolaris maydis race T toxin (T-toxin) on electrolyte leakage from 'W64A' maize leaf segments in normal $(\mathrm{N})$ and Texas male sterile (cms-T) cytoplasm. Leaf strips were infiltrated with T-toxin for $24 \mathrm{~h}$ in the dark at $28^{\circ} \mathrm{C}$ at the concentrations indicated, and then $3-\mathrm{cm}$ leaf segments were immersed in $25 \mathrm{ml}$ of distilled water (DW) and incubated in the dark for another $24 \mathrm{~h}$ at $28^{\circ} \mathrm{C}$. The change in conductivity $(\Delta \mu \mathrm{S} / \mathrm{g}$ of dry weight) of the DW after the first $24 \mathrm{~h}$ is reported. $\mathrm{N}$ and cms-T cytoplasm maize isolines are resistant and susceptible, respectively, to $B$. maydis race $\mathrm{T}$ and $\mathrm{T}$-toxin. Vertical bars delimit \pm standard deviation.

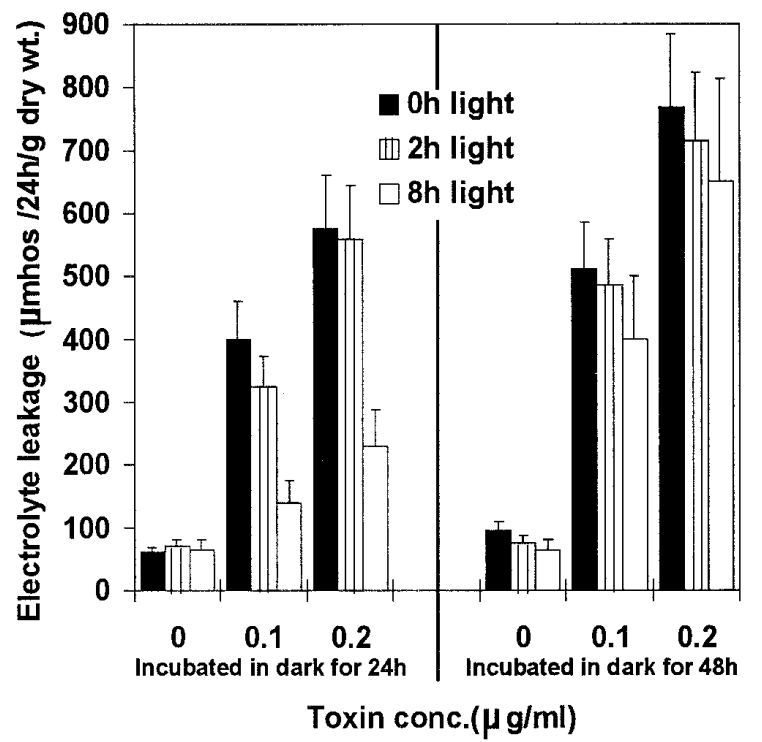

Fig. 2. Effect of a prior exposure to light on the sensitivity of 'W64A' Texas male sterile (cms-T) cytoplasm maize to Bipolaris maydis race $\mathrm{T}$ toxin (T-toxin) as measured by electrolyte leakage. Leaf strips were infiltrated with distilled water (DW) for 0,2 , or $8 \mathrm{~h}$ in the light $\left(50 \mu \mathrm{M} \mathrm{s}^{-1} \mathrm{~m}^{-2}\right)$ prior to infiltration with Ttoxin for $24 \mathrm{~h}$ in the dark at $28^{\circ} \mathrm{C}$, and then $3-\mathrm{cm}$ segments were floated on $25 \mathrm{ml}$ of DW for 24 to $48 \mathrm{~h}$ in the dark. The changes in conductivity after 24 and $48 \mathrm{~h}$ are reported as $\mu \mathrm{S} / 24 \mathrm{~h} / \mathrm{g}$ of dry weight. The 'W64A' cms-T isoline of maize is susceptible to T-toxin. Vertical bars delimit \pm standard deviation. not exposed $(0 \mathrm{~h}$ of light). Moreover, an $8 \mathrm{~h}$ of light pretreatment was more effective in reducing electrolyte loss than was a $2 \mathrm{~h}$ of light pretreatment, which produced a small but insignificant response relative to the $0 \mathrm{~h}$ of light pretreatment. Although this phenomenon was seen with both of the toxin concentrations used, the inhibitory effect of light on toxin-enhanced electrolyte leakage was attenuated when the concentration of toxin used to infiltrate cms-T leaves was increased. Also, the effect of light was nullified when immersed leaf segments were incubated for $48 \mathrm{~h}$ in the dark (Fig. 2).

The cultivars B37 and OH43 in cms-T cytoplasm, which differed in their sensitivity to T-toxin in the dark, were compared to determine whether they also differed when exposed to different light regimes. For this study, leaf strips were preincubated for $8 \mathrm{~h}$, during which time they were exposed to 0,2 , or $8 \mathrm{~h}$ of light and then infiltrated in the dark for another $24 \mathrm{~h}$ in solutions of $2 \%$ ethanol or $2 \%$ ethanol containing approximately $0.2 \mu \mathrm{g}$ of T-toxin per $\mathrm{ml}$. Three-centimeter segments from these strips were immersed in $25 \mathrm{ml}$ of DW and incubated at $28^{\circ} \mathrm{C}$ for a further $48 \mathrm{~h}$ in either dark or light. Leaf segments from 'OH43' cms-T leaked consistently more electrolytes than those from 'B37' cms-T, regardless of the light regime to which they were exposed (Fig. 3). However, for either maize cultivar, preincubation of leaf strips for $8 \mathrm{~h}$ of light, followed by incubation of immersed leaf segments for $48 \mathrm{~h}$ in the dark, resulted in no significant reduction in T-toxin sensitivity as measured by electrolyte loss. In contrast, immersed leaf segments that were postincubated in light for $48 \mathrm{~h}$ were strikingly less sensitive to T-toxin than those postincubated in the dark for all preincubation treatments. The segments from leaf strips that were preincubated in light for $8 \mathrm{~h}$ were the least sensitive to T-toxin (Fig. 3). These data indicate that the reduced sensitivity to T-toxin caused by an initial preincubation period in light may persist for an extended postincubation period in the presence or absence of light. The variation in the sensitivity of cms-T maize to T-toxin has been shown by others to involve variation in the nuclear genome (44).

Time course of electrolyte leakage from cms-T cytoplasm leaves exposed to various light regimes after infiltration with T-toxin. For

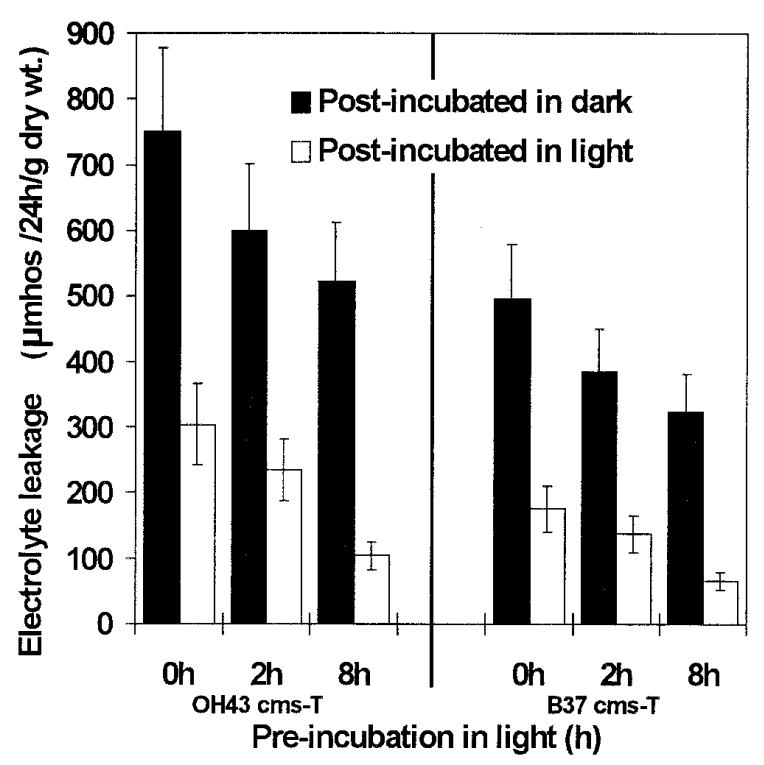

Fig. 3. Electrolyte leakage from Texas male sterile (cms-T) cytoplasm maize leaves exposed to light before and after infiltration with Bipolaris maydis race $\mathrm{T}$ toxin (T-toxin). Replicate leaf strips from 'OH43' cms-T and 'B37' cms-T cultivars were exposed for 0,2 , or $8 \mathrm{~h}$ in the light $\left(50 \mu \mathrm{M} \mathrm{s}^{-1} \mathrm{~m}^{-2}\right)$ prior to infiltration with $0.2 \mu \mathrm{g}$ of T-toxin per $\mathrm{ml}$ for $24 \mathrm{~h}$ in the dark at $28^{\circ} \mathrm{C}$, and then $3-\mathrm{cm}$ leaf segments were immersed in $25 \mathrm{ml}$ of distilled water (DW) and postincubated for another $48 \mathrm{~h}$ in either the light or dark. The changes in conductivity $(\Delta \mu \mathrm{S} / 24 \mathrm{~h} / \mathrm{g}$ of dry weight) after $48 \mathrm{~h}$ are reported. The changes in conductivity of DW with leaves from the 'OH43' cms-T and 'B37' cms-T cultivars not infiltrated with Ttoxin were 65 and $42 \pm 10$, respectively. cms-T cytoplasm isolines of maize are susceptible to T-toxin. Vertical bars delimit \pm standard deviation. 
this study, leaf strips were infiltrated with $2 \%$ ethanol solutions containing $0.2 \mu \mathrm{g}$ of T-toxin per $\mathrm{ml}$ for $24 \mathrm{~h}$ in the dark. They were then were immersed in DW and incubated at $28^{\circ} \mathrm{C}$ for $36 \mathrm{~h}$ in the dark, 12-h intervals in a light-dark-light sequence, 12-h intervals in a dark-light-dark sequence, or $36 \mathrm{~h}$ in the light. Electrolyte leakage from leaves incubated in the dark was significantly higher after 12, 24 , and $36 \mathrm{~h}$ than from leaves incubated in the light (Fig. 4). Leaves incubated under a light-dark-light sequence showed an electrolyte leakage trend similar to that for light for the first $18 \mathrm{~h}$ and one similar to that for dark from 18 to $36 \mathrm{~h}$. In contrast, leaves incubated under a dark-light-dark sequence showed an electrolyte leakage trend that resembled that for dark for the first $18 \mathrm{~h}$ and that for light from 18 to $36 \mathrm{~h}$ (Fig. 4). These data indicated that the inhibitory effect of light on toxin-induced electrolyte leakage from maize leaf segments could be reversed in the dark. Also, the toxin-induced electrolyte leakage that occurred when cms-T leaves were incubated in the dark could be inhibited by their transfer to the light.

Effect of preincubation of T-toxin in light on its potency. We sought to determine whether the decrease in sensitivity to T-toxin observed when leaf segments are incubated in light could be due to inactivation of the T-toxin by the light alone. This was done to validate our assumption that the light effect involved mediating factors and processes in cms-T maize and not a direct inhibition of the T-toxin. For this study, three 5-ml aliquots of toxin $(0.2 \mu \mathrm{g}$ per $\mathrm{ml}$

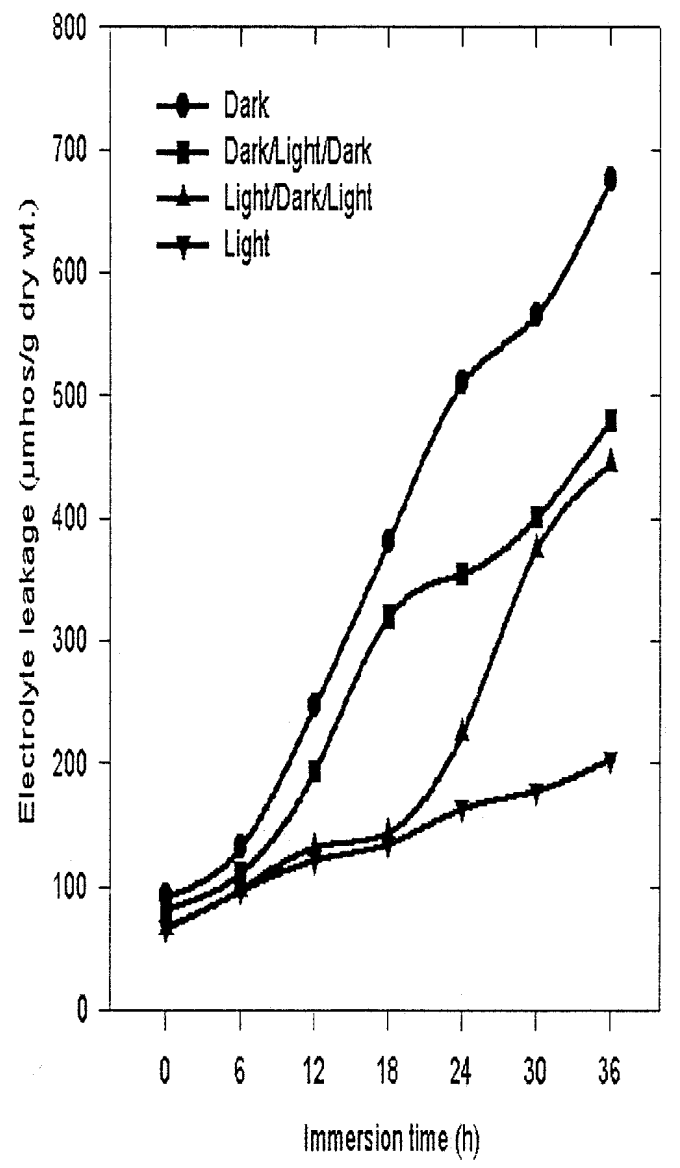

Fig. 4. Time course of electrolyte leakage from Texas male sterile (cms-T) cytoplasm maize leaves exposed to various light regimes following their infiltration with Bipolaris maydis race T toxin (T-toxin). Leaf strips of 'W64A' cms-T maize were infiltrated with $0.2 \mu \mathrm{g}$ of T-toxin per $\mathrm{ml}$ for $24 \mathrm{~h}$ in the dark at $28^{\circ} \mathrm{C}$, and then $3-\mathrm{cm}$ segments were immersed in $25 \mathrm{ml}$ of distilled water (DW) for $36 \mathrm{~h}$ as follows: continuous dark, 12 -h dark +12 -h light +12 -h dark, 12-h light $+12-\mathrm{h}$ dark + $12-\mathrm{h}$ light, and continuous light. Changes in the conductivity ( $\mu \mathrm{S} / \mathrm{g}$ of dry weight) of the DW containing the leaf segments were measured every $6 \mathrm{~h}$. Changes in the conductivity of DW with leaf segments that were not treated with T-toxin was 115 $\pm 22 \mu \mathrm{S} / \mathrm{g}$ of dry weight after $36 \mathrm{~h}$ of incubation in either the dark or light. Each point on the graph is the mean of 10 replications. The standard error was less than $8 \%$ of the mean for each data point. of $2 \%$ ethanol solution) were put into separate vials and preincubated for $24 \mathrm{~h}$ at $28^{\circ} \mathrm{C}$ in either the light $\left(50 \mu \mathrm{M} \mathrm{s}^{-1} \mathrm{~m}^{-2}\right)$ or the dark. Thereafter, leaf strips prepared as described previously were placed in these preincubated T-toxin solutions and incubated for $24 \mathrm{~h}$ in the dark at $28^{\circ} \mathrm{C}$. Leaf segments $(3 \times 1.5 \mathrm{~cm})$ from strips that were treated with this preincubated toxin were then immersed in DW and incubated for another 24 or $48 \mathrm{~h}$ in the dark at $28^{\circ} \mathrm{C}$. Electrolyte leakage was comparable from segments exposed to either lightpreincubated or dark-preincubated toxin. Also, the increase in electrolyte leakage between 24 and $48 \mathrm{~h}$ was comparable for leaf segments exposed to either light- or dark-preincubated T-toxin (Fig. 5). These results indicated that exposure to light for extended periods does not affect T-toxin potency and suggest that light-inactivation of T-toxin may not be the cause of the reduced sensitivity observed when cms-T cytoplasm leaves are exposed to T-toxin in the light.

Effect of malic and aspartic acids on the sensitivity of maize leaves to T-toxin. We evaluated the effect of malate and aspartate on toxin-induced leakage of the electrolytes from $\mathrm{N}$ and cms-T cytoplasm leaves. The impetus for this study came from previous reports that light causes a several-fold increase in the fixation of $\mathrm{CO}_{2}$ into organic and amino acids in plants $(2,25)$. Eighty percent of this $\mathrm{CO}_{2}$ is fixed into $\mathrm{C}_{4}$ acids like malate, aspartate, and oxaloacetate $(2,25,26)$. Therefore, we considered the possibility that metabolites produced by maize leaves in light could affect T-toxin sensitivity. For this reason, the $\mathrm{C}_{4}$ acids malate and aspartate were compared. We immersed T-toxin-infiltrated leaf segments from $\mathrm{N}$ or cms-T cytoplasm maize cultivar W64A in a DW bathing solution with or without 25 or $50 \mu \mathrm{mol}$ of either malate or aspartate and then measured electrolyte leakage after incubating for $24 \mathrm{~h}$ in the dark at $28^{\circ} \mathrm{C}$. The presence of malic acid, but not aspartic acid, in the bathing solution inhibited toxin-induced leakage of electrolytes from cms-T cytoplasm leaf segments (Table 1). The inhibitory effect of malic acid was seen with two different concentrations of T-toxin (Table 2). In contrast, leakage of electrolytes from T-toxin-treated $\mathrm{N}$ cytoplasm leaves was not significantly altered by either malic or aspartic acid (Tables 1 and 2). An increase in the aspartic acid concentration in the DW bathing solution to 100

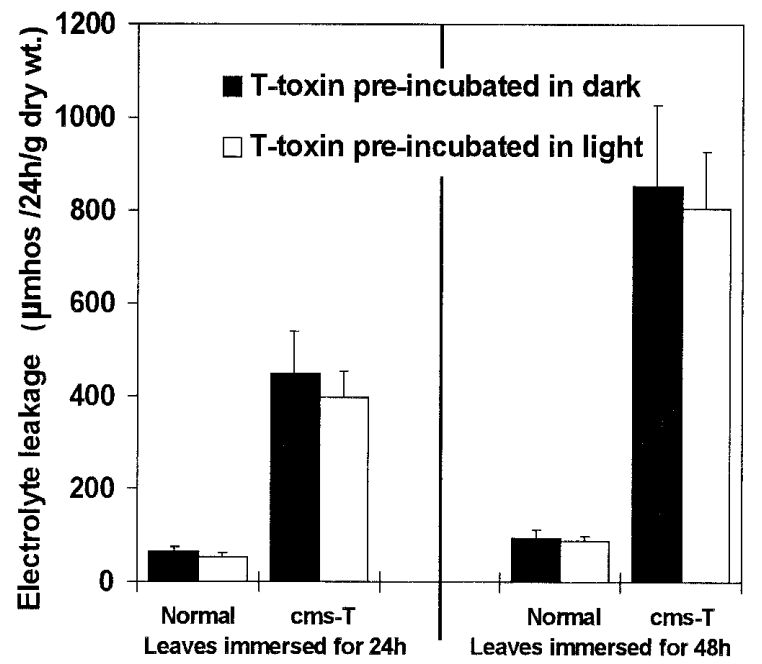

Fig. 5. Effect of preincubation of Bipolaris maydis race T toxin (T-toxin) in either the light or dark on its ability to stimulate electrolyte leakage in normal $(\mathrm{N})$ and Texas male sterile (cms-T) cytoplasm maize leaves. Leaf strips from 'W64A' N and 'W64A' cms-T cytoplasm isolines were infiltrated for $24 \mathrm{~h}$ in the dark with $0.2 \mu \mathrm{g}$ of T-toxin-per-ml solutions that was preincubated for $24 \mathrm{~h}$ at $28^{\circ} \mathrm{C}$ in either the light $\left(50 \mu \mathrm{M} \mathrm{s}^{-1} \mathrm{~m}^{-2}\right)$ or dark. Three-centimeter segments from these leaves were then immersed in $25 \mathrm{ml}$ of distilled water (DW) and incubated in the dark for 24 to $48 \mathrm{~h}$ at $28^{\circ} \mathrm{C}$. Changes in the conductivity $(\Delta \mu \mathrm{S} / 24 \mathrm{~h} / \mathrm{g}$ of dry weight) of the DW containing the leaf segments were measured at 24 and $48 \mathrm{~h}$. N and cms-T cytoplasm maize isolines are resistant and susceptible, respectively, to $B$. maydis race $\mathrm{T}$ and T-toxin. Vertical bars delimit \pm standard deviation. 
or $200 \mu \mathrm{mol}$ caused a similar response in cms-T cytoplasm leaves to that seen for 25 or $50 \mu \mathrm{mol}$ of malic acid (data not shown).

We examined the effect of light and malic acid, alone and in combination, on toxin-induced electrolyte leakage from leaf segments. For this study, three maize cultivars ('B37', 'OH43', and 'W64A') in $\mathrm{N}$ or cms-T cytoplasm were used. Also, the protocol followed was noticeably different from that used in the experiments reported above. Segments were prepared from leaf strips that were first infiltrated only with DW for $24 \mathrm{~h}$ in light at $28^{\circ} \mathrm{C}$. The segments were then immersed into a DW bathing solution containing $0.5 \%$ ethanol and $0.04 \mu \mathrm{g}$ of T-toxin per ml with or without $50 \mu \mathrm{mol}$ of malic acid. The leaf segments immersed in these dilute T-toxin solutions were then incubated for another $24 \mathrm{~h}$ at $28^{\circ} \mathrm{C}$ in either the light or the dark. This altered protocol was adopted because cms-T leaves appeared more sensitive ( 3 to $5 \times$ ) under these assay conditions, and fewer procedures were needed to generate the experimental data. As noted previously, T-toxin caused a severalfold increase in the electrolyte leakage from cms-T cytoplasm leaf segments that were incubated in the dark. The three maize cultivars studied had differing sensitivities to T-toxin. However, they all showed approximately $50 \%$ reduction in electrolyte loss when T-toxin-treated segments were incubated in either the light without malic acid in the bathing solution or the dark with malic acid in the bathing solution (Table 3). Moreover, the stimulatory effect of

TABLE 1. Effects of malate and aspartate on Bipolaris maydis race T (T-toxin)enhanced leakage of electrolytes from normal $(\mathrm{N})$ and Texas male sterile (cms-T) cytoplasm maize leaf segments

\begin{tabular}{lccc}
\hline & $\begin{array}{c}\text { Malate or aspartate } \\
\text { concentration } \\
(\mu \mathrm{M})\end{array}$ & $\begin{array}{c}\text { Electrolyte leakage from T-toxin-infiltrated } \\
\text { leaves }^{\mathrm{a}}(\Delta \mu \mathrm{S} / \mathrm{g} \text { of dry weight in } 24 \mathrm{~h})\end{array}$ \\
\cline { 4 - 4 } & 0 & $163 \pm 34$ & $580 \pm 104$ \\
Malate & 25 & $152 \pm 28$ & $368 \pm 55$ \\
Malate & 50 & $129 \pm 35$ & $194 \pm 21$ \\
Malate & 0 & $143 \pm 22$ & $562 \pm 120$ \\
Aspartate & 25 & $145 \pm 24$ & $440 \pm 95$ \\
Aspartate & 50 & $180 \pm 38$ & $393 \pm 84$ \\
Aspartate & 5 & cms-T cytoplasm $^{\mathrm{b}}$ & \\
\hline
\end{tabular}

${ }^{a}$ Leaf strips of maize cultivar W64A were infiltrated with T-toxin $(0.2 \mu \mathrm{g} / \mathrm{ml})$ for $24 \mathrm{~h}$ in the dark at $28^{\circ} \mathrm{C}$.

${ }^{\mathrm{b}}$ Leaf segments $(3 \times 1.5 \mathrm{~cm})$ were prepared from toxin-infiltrated leaf strips and then immersed in a distilled water bathing solution with or without either malate or aspartate and incubated for $48 \mathrm{~h}$ at $28^{\circ} \mathrm{C}$ in the dark. The initial $\mathrm{pH}$ of the malate and aspartate solutions were adjusted to 6.0 with $0.1 \mathrm{M} \mathrm{NaOH}$. The changes in conductivity per $24 \mathrm{~h}$ are reported for each treatment as $\Delta \mu \mathrm{S} / \mathrm{g}$ of dry weight. Data are the means \pm standard deviations of five replicates and are representative of at least three separate experiments. Electrolyte leakage from $\mathrm{N}$ and cms-T leaf segments not infiltrated with toxin was $89 \pm 31 \mu \mathrm{S} / \mathrm{g}$ of dry weight per $24 \mathrm{~h}$ of incubation.

TABLE 2. Effect of preinfiltration with two Bipolaris maydis race $\mathrm{T}$ (T-toxin) dilutions on leakage of electrolytes from normal $(\mathrm{N})$ and Texas male sterile (cms-T) cytoplasm maize leaf segments that were subsequently immersed for $48 \mathrm{~h}$ in distilled water (DW) bathing solutions with or without $50 \mu \mathrm{M}$ malate

\begin{tabular}{|c|c|c|c|c|}
\hline \multirow{3}{*}{$\begin{array}{l}\text { Toxin concentration } \\
(\mu \mathrm{g} / \mathrm{ml})^{\mathrm{a}}\end{array}$} & \multicolumn{4}{|c|}{$\begin{array}{l}\text { Electrolyte leakage from T-toxin-infiltrated leaves }{ }^{\mathrm{a}} \\
(\Delta \mu \mathrm{S} / \mathrm{g} \text { of dry weight in } 24 \mathrm{~h})\end{array}$} \\
\hline & \multicolumn{2}{|c|}{ N cytoplasm ${ }^{b}$} & \multicolumn{2}{|c|}{ cms-T cytoplasm ${ }^{b}$} \\
\hline & - Malate & + Malate & - Malate & + Malate \\
\hline Contr & $104 \pm 20$ & $88 \pm$ & $122 \pm 14$ & $106 \pm 28$ \\
\hline 0.1 & $116 \pm 25$ & $101 \pm 23$ & $230 \pm 42$ & $118 \pm 22$ \\
\hline 0.2 & $131 \pm 28$ & $95 \pm 24$ & $620 \pm 85$ & $264 \pm 59$ \\
\hline
\end{tabular}

${ }^{a}$ Leaf strips of maize cultivar W64A were infiltrated with either DW or toxin solutions for $24 \mathrm{~h}$ in the dark at $28^{\circ} \mathrm{C}$.

${ }^{\mathrm{b}}$ Leaf segments $(3 \times 1.5 \mathrm{~cm})$ were prepared from leaf strips that were infiltrated with DW or toxin solutions and then immersed in a DW bathing solution and incubated for $48 \mathrm{~h}$ at $28^{\circ} \mathrm{C}$ in the dark. The initial $\mathrm{pH}$ of the malate solution was adjusted to 6.0 with $0.1 \mathrm{M} \mathrm{NaOH}$. The changes in conductivity per $24 \mathrm{~h}$ are reported for each treatment as $\Delta \mu \mathrm{S} / \mathrm{g}$ of dry weight. Data are the means \pm standard deviations of five replicates and are representative of at least three separate experiments.
T-toxin on electrolyte leakage, seen in the dark, was completely suppressed when T-toxin-treated leaf segments that were immersed in a toxin-containing bathing solution with malic acid were also exposed to light (Table 3). No such responses to light or malic acid were seen in T-toxin-treated $\mathrm{N}$ cytoplasm segments.

Effect of $\mathrm{H}_{2} \mathrm{O}_{2}$ on T-toxin-induced electrolyte leakage from cms-T cytoplasm leaves. We were motivated to do this experiment because preliminary tests showed that, after $48 \mathrm{~h}$ in bathing solutions containing cms-T cytoplasm maize leaf segments, residual levels of hydrogen peroxide $\left(\mathrm{H}_{2} \mathrm{O}_{2}\right)$ were up to $80 \%$ higher in the light than in the dark. Also, leaf segments had decreased sensitivity to T-toxin when they were immersed in DW containing 25 or more $\mu \mathrm{mol}$ of $\mathrm{H}_{2} \mathrm{O}_{2}$, but not when immersed in DW containing $\mathrm{H}_{2} \mathrm{O}_{2}$ plus $8 \times 10^{-4} \mu \mathrm{g}$ of catalase per ml. These observations were taken to mean that alterations in $\mathrm{H}_{2} \mathrm{O}_{2}$ levels might be involved in the altered sensitivity of cms-T cytoplasm maize leaves to light and malic acid. $\mathrm{H}_{2} \mathrm{O}_{2}$ is one of the AOS that are typically produced when plant tissues are exposed to light $(7,41)$ or to stress metabolites associated with plant-microbe interactions $(1,32)$. Also, malate, which accumulates in plant leaves in response to light,

TABLE 3. Effect of light on leakage of electrolytes from leaf segments of three maize cultivars in normal $(\mathrm{N})$ and Texas male sterile (cms-T) cytoplasm after they were immersed in a distilled water (DW) bathing solution containing $0.04 \mu \mathrm{g}$ of Bipolaris maydis race T (T-toxin) per $\mathrm{ml}$ with or without malate

\begin{tabular}{|c|c|c|c|c|c|}
\hline \multirow[b]{3}{*}{ Treatment $^{\mathrm{a}}$} & \multirow{3}{*}{$\begin{array}{l}\text { Maize } \\
\text { cultivar }\end{array}$} & \multicolumn{4}{|c|}{$\begin{array}{l}\text { Electrolyte leakage from toxin-treated leaf } \\
\text { segments }^{\text {b }}(\Delta \mu \mathrm{S} / \mathrm{g} \text { of dry weight in } 24 \mathrm{~h})\end{array}$} \\
\hline & & \multicolumn{2}{|c|}{$\mathrm{N}$ cytoplasm } & \multicolumn{2}{|c|}{ cms-T cytoplasm } \\
\hline & & Dark & Light & Dark & Light \\
\hline Control & B37 & $135 \pm 34$ & $214 \pm 56$ & $510 \pm 88$ & $243 \pm 41$ \\
\hline Malate $(50 \mu \mathrm{M})$ & B37 & $171 \pm 36$ & $168 \pm 31$ & $255 \pm 47$ & $124 \pm 27$ \\
\hline Control & $\mathrm{OH} 43$ & $216 \pm 31$ & $281 \pm 54$ & $721 \pm 102$ & $357 \pm 56$ \\
\hline Malate $(50 \mu \mathrm{M})$ & $\mathrm{OH} 43$ & $247 \pm 52$ & $226 \pm 44$ & $340 \pm 74$ & $165 \pm 25$ \\
\hline Control & W64A & $183 \pm 31$ & $246 \pm 54$ & $620 \pm 146$ & $284 \pm 63$ \\
\hline Malate $(50 \mu \mathrm{M})$ & W64A & $204 \pm 42$ & $195 \pm 34$ & $289 \pm 64$ & $154 \pm 43$ \\
\hline
\end{tabular}

${ }^{a}$ Leaf strips from maize cultivars B37, OH43, and W64A were infiltrated with DW for $24 \mathrm{~h}$ in the light $\left(50 \mu \mathrm{M} \mathrm{s}^{-1} \mathrm{~m}^{-2}\right)$ at $28^{\circ} \mathrm{C}$, cut into $3 \times 1.5-\mathrm{cm}$ segment, and then immersed in a DW bathing solution containing $0.04 \mu \mathrm{g}$ of toxin per $\mathrm{ml}$ with or without malate $(50 \mu \mathrm{M})$. The initial $\mathrm{pH}$ of the malate solution was adjusted to 6.0 with $0.1 \mathrm{M} \mathrm{NaOH}$.

${ }^{\mathrm{b}}$ Leaf segments $(3 \times 1.5 \mathrm{~cm})$ in the bathing solutions were incubated for $48 \mathrm{~h}$ at $28^{\circ} \mathrm{C}$ in either the dark or the light. The changes in conductivity $(\Delta \mu \mathrm{S} / \mathrm{g}$ of dry weight) per $24 \mathrm{~h}$ are the means \pm standard deviations of five replicates and are representative of at least three separate experiments. Conductivity changes in solutions with $\mathrm{N}$ and cms- $\mathrm{T}$ cytoplasm leaf segments not treated with T-toxin were the same as those for toxin-treated $\mathrm{N}$ cytoplasm ones.

TABLE 4. Effects of malate, hydrogen peroxide, and light on leakage of electrolytes from leaf segments of two maize cultivars in Texas male sterile (cms-T) cytoplasm after they were immersed in distilled water (DW) bathing solutions with and without $0.04 \mu \mathrm{g}$ of Bipolaris maydis race T (T-toxin) per $\mathrm{ml}$

\begin{tabular}{|c|c|c|c|c|c|}
\hline \multirow[b]{3}{*}{ Treatment $^{\mathrm{a}}$} & \multirow{3}{*}{$\begin{array}{l}\text { Maize } \\
\text { cultivar }\end{array}$} & \multicolumn{4}{|c|}{$\begin{array}{l}\text { Electrolyte leakage from leaf segments } \\
(\Delta \mu \mathrm{S} / \mathrm{g} \text { of dry weight in } 24 \mathrm{~h})\end{array}$} \\
\hline & & \multicolumn{2}{|c|}{ Dark } & \multicolumn{2}{|c|}{ Light } \\
\hline & & - Toxin & + Toxin & - Toxin & + Toxin \\
\hline Control & B37 & $220 \pm 31$ & $564 \pm 64$ & $184 \pm 29$ & $214 \pm 42$ \\
\hline Malate $(50 \mu \mathrm{M})$ & B37 & $170 \pm 28$ & $310 \pm 33$ & $168 \pm 32$ & $195 \pm 24$ \\
\hline $\mathrm{H}_{2} \mathrm{O}_{2}(25 \mu \mathrm{M})$ & B37 & $145 \pm 28$ & $176 \pm 32$ & $136 \pm 31$ & $168 \pm 27$ \\
\hline Control & $\mathrm{OH} 43$ & $287 \pm 41$ & $688 \pm 73$ & $280 \pm 36$ & $374 \pm 51$ \\
\hline Malate $(50 \mu \mathrm{M})$ & $\mathrm{OH} 43$ & $240 \pm 37$ & $360 \pm 44$ & $215 \pm 32$ & $290 \pm 42$ \\
\hline $\mathrm{H}_{2} \mathrm{O}_{2}(25 \mu \mathrm{M})$ & $\mathrm{OH} 43$ & $229 \pm 35$ & $256 \pm 37$ & $160 \pm 26$ & $188 \pm 17$ \\
\hline
\end{tabular}

${ }^{a}$ Leaf strips from maize cultivars B37 and OH43 were infiltrated with DW for $24 \mathrm{~h}$ in the light $\left(50 \mu \mathrm{M} \mathrm{s}^{-1} \mathrm{~m}^{-2}\right)$ at $28^{\circ} \mathrm{C}$, cut into $3 \times 1.5-\mathrm{cm}$ segments, and then immersed in a DW bathing solutions with or without $0.04 \mu \mathrm{g}$ of T-toxin malate $(50 \mu \mathrm{M})$ or $\mathrm{H}_{2} \mathrm{O}_{2}(25 \mu \mathrm{M})$ per ml. The initial $\mathrm{pH}$ of the solution was 6.0.

${ }^{b}$ Leaf segments $(3 \times 1.5 \mathrm{~cm})$ in the bathing solution were incubated for $48 \mathrm{~h}$ at $28^{\circ} \mathrm{C}$ in either the dark or the light. The changes in conductivity $(\Delta \mu \mathrm{S} / \mathrm{g}$ of dry weight) per $24 \mathrm{~h}$ are the means \pm standard deviations of five replicates and are representative of at least three separate experiments. 
could serve as a precursor for intermediates whose metabolism is accompanied by the formation of $\mathrm{H}_{2} \mathrm{O}_{2}$ (46). Therefore, the possibility that light- and malate-generated $\mathrm{H}_{2} \mathrm{O}_{2}$ might be involved with the reduced susceptibility of $\mathrm{cms}-\mathrm{T}$ maize to T-toxin is of interest. For this study, segments from cms-T cytoplasm leaf strips were immersed into a bathing solution containing a very dilute solution of T-toxin $(0.04 \mu \mathrm{g}$ per $\mathrm{ml}$ of $0.5 \%$ ethanol solution) with or without $25 \mu \mathrm{mol}$ of $\mathrm{H}_{2} \mathrm{O}_{2}$ or $50 \mu \mathrm{mol}$ of malate, and then incubated for $48 \mathrm{~h}$ at $28^{\circ} \mathrm{C}$ in either the dark or the light. For both cultivars B37 and $\mathrm{OH} 43$, the loss of electrolytes caused by T-toxin treatment in the dark was significantly reduced when either $\mathrm{H}_{2} \mathrm{O}_{2}$ or malate was in the bathing solution (Table 4). There was a similar response when T-toxin-treated segments were incubated in the light without either $\mathrm{H}_{2} \mathrm{O}_{2}$ or malate. Moreover, with either maize cultivar, the combination of light and $\mathrm{H}_{2} \mathrm{O}_{2}$ or light and malate appeared to be more effective in reducing the T-toxin-induced loss of electrolytes than either treatment alone (Table 4).

\section{DISCUSSION}

We have demonstrated that the exposure of cms-T cytoplasm maize leaves to light reduces their sensitivity to $B$. maydis race $\mathrm{T}$ toxin. cms-T leaves treated with T-toxin and kept in light lost less electrolytes than similar leaves that were kept in the dark. Also, cms-T leaves that were exposed to intermittent 12 -h periods of light and dark, following T-toxin treatment in the dark, showed intermediate levels of sensitivity to T-toxin, as measured by the quantity of electrolyte leakage. These findings, together with our observation that the toxin is not inactivated by direct exposure to light of the intensity used in our study, leads to the conclusion that physiological changes in cms- $T$ leaves, rather than light-induced changes in the potency of the toxin, might be involved. The results are consistent with those of others who reported on the protective effect of light on the action of T-toxin. For example, the collapse of T-toxin-treated protoplasts was prevented by light (13). Similarly, protoplasts from green leaves that had been exposed to light before T-toxin treatment became insensitive to the toxin (35). In related studies, Walton et al. (50) noted that the T-toxin-induced reduction in ATP in protoplasts incubated in the dark was alleviated in the light. This response was abolished in the presence of 3-(3,4-dichlorophenyl)-1,1-dimethylurea (DCMU), an inhibitor of photosynthetic electron transport. Based on these findings, they concluded that light-driven ATP synthesis compensated for that which was lost due to inhibition by Ttoxin of oxidative phosphorylation in mitochondria.

Previous reports have shown that light stimulates the fixation of $\mathrm{CO}_{2}$ into malate and other organic acids in $\mathrm{C}_{4}$ plants like maize $(2,26,29)$, as well as plants with crassulacean acid metabolism $(8$, $42,48)$. Also, the level of $\mathrm{C}_{4}$ acids in mesophyll cells enhances the light-stimulated fixation of $\mathrm{CO}_{2}$ into these same acids, indicating that $\mathrm{C}_{4}$ acids and light produce additive effects (26). Further, the level of $\mathrm{C}_{4}$ organic acids in leaves fluctuate in parallel with the diurnal periodicity of light $(42,48)$ in a way that is reminiscent of the patterns of sensitivity to toxin seen when toxin-treated cms-T cytoplasm leaves were exposed to intermittent 12-h periods of light and dark (Fig. 4). Moreover, it is worth noting that, in $\mathrm{C}_{4}$ plants, the organic acid pool is typically $1.0 \mu \mathrm{mol} / \mathrm{g}$ of fresh weight or more. Also, in plants with crassulacean acid metabolism, the malate pool may peak at $15.0 \mu \mathrm{mol} / \mathrm{g}$ of fresh weight (42). We noted that infiltration of cms-T cytoplasm maize leaves with a solution containing physiological concentrations of malate (Tables 1 to 4) caused a reduction in their sensitivity to T-toxin in the dark. This is consistent with our view that malate may have played a mediating role in reducing the sensitivity of cms-T maize to T-toxin at the relatively low intensities or dosages of light used in this study.

One possible explanation of the light effect is that it raises the levels of reduced cofactors and Calvin cycle intermediates and causes respiratory rates to exceed the demands of the maize leaf cells for ATP. As a result, electrons may spill over into other path- ways, some of which involve the formation of AOS. It is assumed that one or more of these AOS might, by mechanisms that are not yet understood, interfere with the ability of T- toxin to disrupt key functions of cms-T mitochondria.

We observed that malate mimics the light effect. Also, aspartate appeared to produce a similar response to malate, but at two- or threefold higher concentrations (data not shown). Others $(19,43)$ have reported that state 4 respiration is inhibited when toxin-treated mitochondria from cms-T maize are incubated with malate. This could mean there is a diversion of the flow of electrons from their usual path to oxygen as a terminal acceptor. Therefore, the explanation for the light effect proposed above may apply to that for malate and other $\mathrm{C}_{4}$ metabolites as well. Alternatively, malate itself may contribute to $\mathrm{H}_{2} \mathrm{O}_{2}$ formation if physiological conditions are favorable $(21,46)$. Interestingly, the mechanism of the light-induced insensitivity of cms-T maize to T-toxin proposed here is not incompatible with that enunciated by Walton et al. (50), who suggested that the protection of maize leaves from the action of toxin in light is associated with light-driven phosphorylation that compensates for toxin-induced inactivation of oxidative phosphorylation. However, this is the first time consideration has been given to a possible role for AOS in the light response of cms-T maize to T-toxin. Further studies involving the interaction of $\mathrm{H}_{2} \mathrm{O}_{2}$ with the sensitivity of cms-T maize to T-toxin are in progress.

It is noteworthy that $\mathrm{H}_{2} \mathrm{O}_{2}$ can substitute for light and malate to reduce the sensitivity of cms-T cytoplasm maize leaves to T-toxin (Table 4). This is consistent with the idea that AOS might be involved. Since AOS are often implicated with disease resistance responses in plants $(1,32,34,54)$, follow-up studies with $\mathrm{H}_{2} \mathrm{O}_{2}$ could lead to new insights into the mechanism(s) of light- and malate-induced insensitivity of cms-T maize to T-toxin. At any rate, the results of this study point to the possibility that, in addition to light-driven phosphorylation, AOS, particularly $\mathrm{H}_{2} \mathrm{O}_{2}$, may be involved with various effects of environmental factors on the sensitivity of cms-T maize to T-toxin.

Also, the work presented could set the stage for more critical studies on the implications for plant-microbe interactions of light effects and altered levels of $\mathrm{C}_{4}$ metabolites. In this connection, Daly and Livne (10) noted that more ${ }^{14} \mathrm{C}$ from ${ }^{14} \mathrm{C}$-labeled bicarbonate was incorporated into organic acids when either healthy or rusted wheat leaves were incubated for $5 \mathrm{~h}$ in the light than when similar leaves were incubated in the dark. Also, Malca and Zscheile (36) noted that malic acid levels were higher in infected leaves of seedlings of a maize isoline $\left(\operatorname{Pr}_{1}\right)$ that was resistant to race 1 of $H$. carbonum than in an infected isoline that was susceptible (Pr). They observed a higher malic acid content in seedlings of the $\operatorname{Pr}$ isoline of maize that were inoculated with race 2 of $H$. carbonum (incompatible) instead of race 1 (compatible).

The results of the current study and the interpretations presented could add new insights into the large body of knowledge that already exist on the mode of action of T-toxin and on the nature of the responses of maize to it. Also, these studies could give renewed significance to earlier investigations on the effects of light and organic acids on host-parasite interactions including those of Malca and Zscheile (36), Daly and Livne (10), Bhullar et al. (6), Daly and Barna (9), Walton et al. (50), and MacRae and Yoder (35).

\section{ACKNOWLEDGMENTS}

Supported, in part, by state and federal funds appropriated to The Ohio Agricultural Research and Development Center, The Ohio State University. Submitted as journal article 208-95 from The Ohio Agricultural Research and Development Center. We thank T. L. Graham and P. E. Lipps for their reviews and discussions.

\section{LITERATURE CITED}

1. Baker, C. J., and Orlandi, E. W. 1995. Active oxygen in plant pathogenesis. Annu. Rev. Phytopathol. 33:299-321.

2. Baldry, C. W., Bucke, C., and Coombs, J. 1969. Light/phosphoenolpyruvate-dependent carbon dioxide fixation by isolated sugar cane chloro- 
plasts. Biochem. Biophys. Res. Commun. 37:828-832.

3. Bednarski, M. A., Izawa, S., and Scheffer, R. P. 1977. Reversible effects of toxin from Helminthosporium maydis race $\mathrm{T}$ on oxidative phosphorylation by mitochondria from maize. Plant Physiol. 59:540-545.

4. Beltran, J. D., and Garraway, M. O. 1996. The sensitivity of Texas male sterile cytoplasm maize leaves to Bipolaris maydis race $\mathrm{T}$ toxin is decreased by light. (Abstr.) Phytopathology 86:S26.

5. Bervillé, A., Ghazi, A., Charbonnier, M., and Bonavent, J. F. 1984. Effects of methomyl and Helminthosporium maydis toxin on matrix volume, proton motive force and NAD accumulation in maize (Zea mays L.) mitochondria. Plant Physiol. 76:508-517.

6. Bhullar, B. S., Daly, J. M., and Rehfeld, D. W. 1975. Inhibition of dark $\mathrm{CO}_{2}$ fixation and photosynthesis in leaf discs of corn susceptible to the host-specific toxin produced by Helminthosporium maydis, race T. Plant Physiol. 56:1-7.

7. Chamnongpol, S., Willekens, H., Langebartels, C., VanMontagu, M., Inze, D., and VanCamp, W. 1996. Transgenic tobacco with a reduced catalase activity develops necrotic lesions and induces pathogenesis-related expression under high light. Plant J. 10:491-503.

8. Cockburn, W., and McAulay, A. 1977. Changes in metabolite levels in Kalanchoë daigremonitiana and the regulation of malic acid in crassulacean acid metabolism. Plant Physiol. 59:455-458.

9. Daly, J. M., and Barna, B. 1980. A differential effect of race T toxin on dark and photosynthetic carbon dioxide fixation by thin leaf slices from susceptible corn (Zea mays). Plant Physiol. 66:580-583.

10. Daly, J. M., and Livne, A. 1966. Dark fixation of carbon dioxide by healthy and rust-affected leaves of wheat and bean. Phytopathology 56:164-169.

11. Dewey, R. E., Siedow, J. N., Timothy, D. H., and Levings, C. S., III. 1988. A 13-kilodalton maize mitochondrial protein in E. coli confers sensitivity to Bipolaris maydis toxin. Science 239:293-295.

12. Dewey, R. E., Timothy, D. H., and Levings, C. S., III. 1987. A mitochondrial protein associated with cytoplasmic male sterility in the $\mathrm{T}$ cytoplasm of maize. Proc. Natl. Acad. Sci. U.S.A. 84:5374-5378.

13. Earle, E. D., Gracen, V. E., Yoder, O. C., and Gemmill, K. P. 1978. Cytoplasm-specific effects of Helminthosporium maydis race $\mathrm{T}$ toxin on survival of corn mesophyll protoplasts. Plant Physiol. 61:420-424.

14. Fierabend, J., Schaan, C., and Hertwig, B. 1992. Photoinactivation of catalase occurs under both high- and low-temperature stress conditions and accompanies photoinhibition of photosystem II. Plant Physiol. 100:1554-1561.

15. Gardeström, P., and Edwards, G. E. 1985. Leaf mitochondria $\left(\mathrm{C}_{3}+\mathrm{C}_{4}+\right.$ CAM). Pages 314-346 in: Encyclopedia of Plant Physiology New Series Vol. 18. R. Douce and D. A. Day, eds. Springer, New York.

16. Garraway, M. O. 1973. Electrolyte and peroxidase leakage as indicators of susceptibility of various maize inbreds to Helminthosporium maydis races $\mathrm{O}$ and T. Plant Dis. Rep. 57:518-522.

17. Garraway, M. O., Akhtar, M., and Wokoma, E. C. W. 1989. Effect of high temperature stress on peroxidase activity and electrolyte leakage in maize in relation to sporulation of Bipolaris maydis race T. Phytopathology 79: 800-805.

18. Garraway, M. O., and Evans, R. C. 1977. Sporulation in Bipolaris maydis: Enhancement by xylose. Phytopathology 67:990-993.

19. Gengenbach, B. G., Miller, R. J., Koeppe, D. E., and Arntzen, C. J. 1973. The effect of toxin from Helminthosporium maydis (race $\mathrm{T}$ ) on isolated corn mitochondria: Swelling. Can. J. Bot. 51:2119-2125.

20. Glab, N., Wise, R. P., Pring, D. R., Jacq, C., and Slonlmski, P. 1980. Expression in Saccharomyces cerevisiae of a gene associated with cytoplasmic male sterility from maize: Respiratory dysfunction and uncoupling of yeast mitochondria. Mol. Gen. Genet. 223:24-32.

21. Gross, G. G., and Elstner, E. F. 1977. Involvement of malate, monophenols, and superoxide radical in hydrogen peroxide formation by isolated cell walls from horseradish (Amoracia lapathifolia Gilib). Planta 136:271-276.

22. Hakam, N., and Simon, J.-P. 1996. Effect of low temperatures on the activity of oxygen-scavenging enzymes in two populations of the $\mathrm{C}_{4}$ grass Echinochloa crusgalli. Physiol. Plant. 97:209-216.

23. Hatch, M. D., and Osmond, C. B. 1976. Compartmentation and metabolite transport in $\mathrm{C}_{4}$ photosynthesis. Pages 144-184 in: Encyclopedia of Plant Physiology New Series Vol. 3. C. R. Stocking and U. Heber, eds. Springer, New York.

24. Holden, M. J., Columbini, M., and Sze, H. 1985. Channel formation in phospholipid bilayer membranes by the toxin of Helminthosporium maydis, race T. J. Membr. Biol. 87:151-157.

25. Huber, S. C., and Edwards, G. L. 1975. C 4 photosynthesis: Light-dependent $\mathrm{CO}_{2}$ fixation by mesophyll cells, protoplasts and protoplast extracts of Digitaria sanguinalis. Plant Physiol. 55:835-844.

26. Huber, U. 1974. Metabolite exchange between chloroplast and cytoplasm. Annu. Rev. Plant Physiol. 25:393-421.

27. Jahnke, L. S., Hull, M. R., and Long, S. P. 1991. Chilling stress and oxygen metabolizing enzymes in Zea mays and Zea diploperennis. Plant Cell Environ. 14:97-104.

28. Kagawa, T., and Hatch, M. D. 1974. Light-dependent metabolism of carbon compounds by mesophyll chloroplasts from plants with the $\mathrm{C}_{4}$ pathway of photosynthesis. Aust. J. Plant Physiol. 1:51-64.

29. Kagawa, T., and Hatch, M. D. 1974. $\mathrm{C}_{4}$-acids as the source of carbon dioxide for Calvin cycle photosynthesis by bundle sheath cells of the $\mathrm{C}_{4^{-}}$ pathway species Atriplex spongiosa. Biochem. Biophys. Res. Commun. 59:1326-1332.

30. Kimber, A., and Sze, H. 1984. Helminthosporium maydis T toxin decreased calcium transport into mitochondria of susceptible corn. Plant Physiol. 74:804-809.

31. Klein, R. R., and Koeppe, D. E. 1985. Mode of methomyl and Bipolaris maydis (race $\mathrm{T}$ ) toxin in uncoupling Texas male-sterile cytoplasm corn (Zea mays) mitochondria. Plant Physiol. 77:912-916.

32. Lamb, C., and Dixon, R. A. 1997. The oxidative burst in plant disease resistance. Annu. Rev. Plant Physiol. Plant Mol. Biol. 48:251-275.

33. Levings, C. S., III. 1990. The Texas cytoplasm of maize: Cytoplasmic male sterility and disease susceptibility. Science 250:942-947.

34. Low, P. S., and Merida, J. R. 1996. The oxidative burst in plant defense: Function and signal transduction. Physiol. Plant. 96:533-542.

35. MacRae, W. D., and Yoder, O. C. 1988. Light has opposite effects on sensitivity of maize protoplasts to T-toxin from Cochliobolus heterostrophus. Physiol. Mol. Plant Pathol. 32:293-300.

36. Malca, I., and Zscheile, F. P., Jr. 1963. Effect of the Helminthosporium leafspot disease on organic acid content of corn seedlings. Phytopathology 53:341-343

37. Matthews, D. E., Gregory, P., and Gracen, V. E. 1979. Helminthosporium maydis race $\mathrm{T}$ toxin induces leakage of $\mathrm{NAD}^{+}$from $\mathrm{T}$ cytoplasm corn mitochondria. Plant Physiol. 63:1149-1153.

38. Mertz, S. M., Jr., and Arntzen, C. J. 1977. Selective inhibition of $\mathrm{K}^{+}$, $\mathrm{Na}^{+}, \mathrm{Cl}^{-}$and $\mathrm{PO}_{4}{ }^{3-}$ uptake in Zea mays L. by Bipolaris (Helminthosporium) maydis race T pathotoxin. Plant Physiol. 60:363-369.

39. Mertz, S. M., Jr., and Arntzen, C. J. 1978. Depolarization of the electromagnetic transmembrane potential of Zea mays L. by Bipolaris (Helminthosporium) maydis race $\mathrm{T}$ toxin, azide, cyanide, dodecyl succinic acid, or cold temperature. Plant Physiol. 62:781-783.

40. Miller, R. J., and Koeppe, D. E. 1971. Southern corn leaf blight: Susceptible and resistant mitochondria. Science 173:67-69.

41. Mtolera, S. P., Collen, J., Pedersen, M., and Semesi, A. K. 1995. Destructive hydrogen peroxide production in Eucheuma denticulatum (Rhodophyta) during stress caused by elevated $\mathrm{pH}$, high light intensities and competition with other species. Eur. J. Phycol. 30:289-297.

42. Osmond, C. B. 1978. Crassulacean acid metabolism: A curiosity in context. Annu. Rev. Plant Physiol. 29:379-414

43. Payne, G., Knoche, H. W., Kono, Y., and Daly, J. M. 1980. Biological activity of purified host-specific pathotoxin produced by Bipolaris (Helminthosporium) maydis, race T. Physiol. Plant Pathol. 16:227-239.

44. Payne, G. A., and Yoder, O. C. 1978. Effect of the nuclear genome of corn on sensitivity to Helminthosporium maydis race T-toxin and on susceptibility to $H$. maydis race T. Phytopathology 68:331-337.

45. Payne, G. A., and Yoder, O. C. 1978. Production and some characteristics of host-specific toxin(s) produced by several isolates of Helminthosporium maydis race T. Phytopathology 68:707-714.

46. Peng, M., and Kuc, J. 1992. Peroxidase-generated hydrogen peroxide as a source of antifungal activity in vitro and on tobacco leaf disks. Phytopathology 82:696-699.

47. Pring, D. R., and Lonsdale, D. M. 1989. Cytoplasmic male sterility and maternal inheritance of disease susceptibility in maize. Annu. Rev. Phytopathol. 27:483-502.

48. Sutton, B. G., and Osmond, C. B. 1972. Dark $\mathrm{CO}_{2}$ fixation by crassulacean plants. Plant Physiol. 50:360-365.

49. Umbeck, P. F., and Gengenbach, B. G. 1983. Reversion of male-sterile Tcytoplasm maize to male fertility in tissue culture. Crop Sci. 23:584-588.

50. Walton, J. D., Earle, E. D., Yoder, O. C., and Spanswick, R. M. 1979. Reduction in adenosine triphosphate levels in susceptible maize mesophyll protoplasts by Helminthosporium maydis race $\mathrm{T}$ toxin. Plant Physiol. 63:806-810.

51. Wheeler, H., Williams, A. S., and Young, L. D. 1971. Helminthosporium maydis T-toxin as an indicator of resistance to southern corn leaf blight. Plant Dis. Rep. 55:667-671.

52. Wise, R. P., Fliss, A. E., Pring, D. R., and Gengenbach, B. G. 1987. URF13-T of T cytoplasm maize mitochondria encodes a $13 \mathrm{kD}$ polypeptide. Plant Mol. Biol. 9:121-126.

53. Wise, R. P., Pring, D. R., and Gengenbach, B. G. 1987. Mutation to male fertility and toxin insensitivity in Texas (T)-cytoplasm maize is associated with a frame shift in a mitochondrial open reading frame. Proc. Natl. Acad. Sci. U.S.A. 84:2858-2862.

54. Wu, G., Shortt, B. J., Lawrence, E. B., Levine, E. B., Fitzsimmons, K. C., and Shah, D. M. 1995. Disease resistance conferred by expression of a gene encoding $\mathrm{H}_{2} \mathrm{O}_{2}$-generating glucose oxidase in transgenic potato plants. Plant Cell 7:1357-1368. 